\title{
A rare skin burn during endoscopic submucosal dissection
}

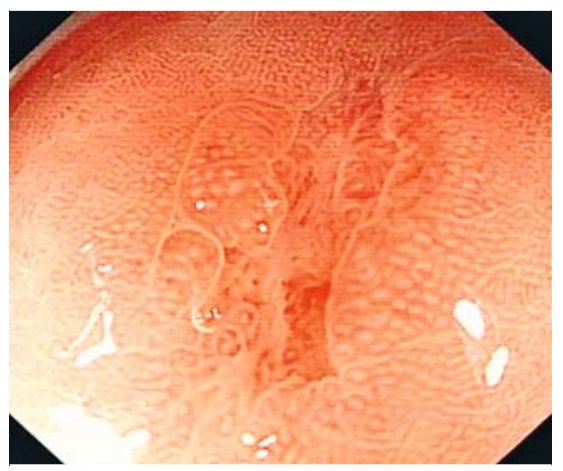

Fig. 1 The early gastric cancer.

A 54-year-old woman was diagnosed with early gastric cancer (EGC) in the gastric antrum during screening examination ( Fig.1a). The EGC was successfully removed using an insulated-tip knife (Endocut I, Effect 3, Duration 2, Interval 4; ERBE Elektromedizin, Tübingen, Germany) ( $\triangleright$ Fig. 2). Unfortunately, we noticed after the procedure that the skin on the patient's back, where the electrode pad had been placed, was severely burnt ( $\triangleright$ Fig. 3 , \Video 1 ). The patient recovered in a week after applying recombinant human epidermal growth factor gel to the burn.

Endoscopic submucosal dissection (ESD) is extensively used to treat lesions of the gastrointestinal tract, with bleeding and perforation being the most common complications [1]. However, rare cases of skin burn have also been recorded. Miyaga et al. reported that five patients experienced precordial skin burns after ESD when removing lesions from the upper or middle portion of a reconstructed gastric tube through the presternal route, owing to the gastric tube being positioned too close to the precordial skin [2]. However, no case of skin burn from the electrode pad has been reported. To the best of our knowledge, this was the first case of skin burn out of
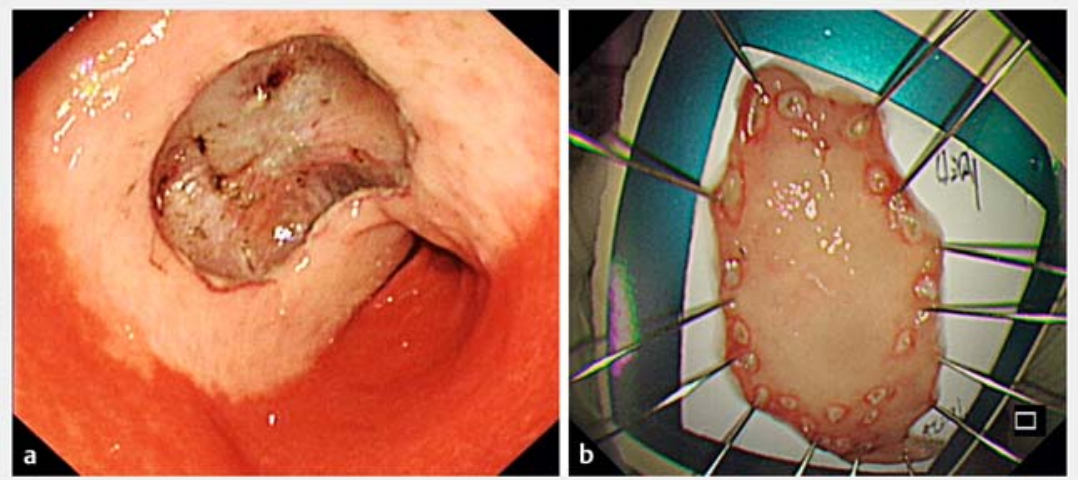

- Fig. 2 Endoscopic submucosal resection was performed for early gastric cancer. a The defect after removal of the tumor. $\mathbf{b}$ The resection specimen.

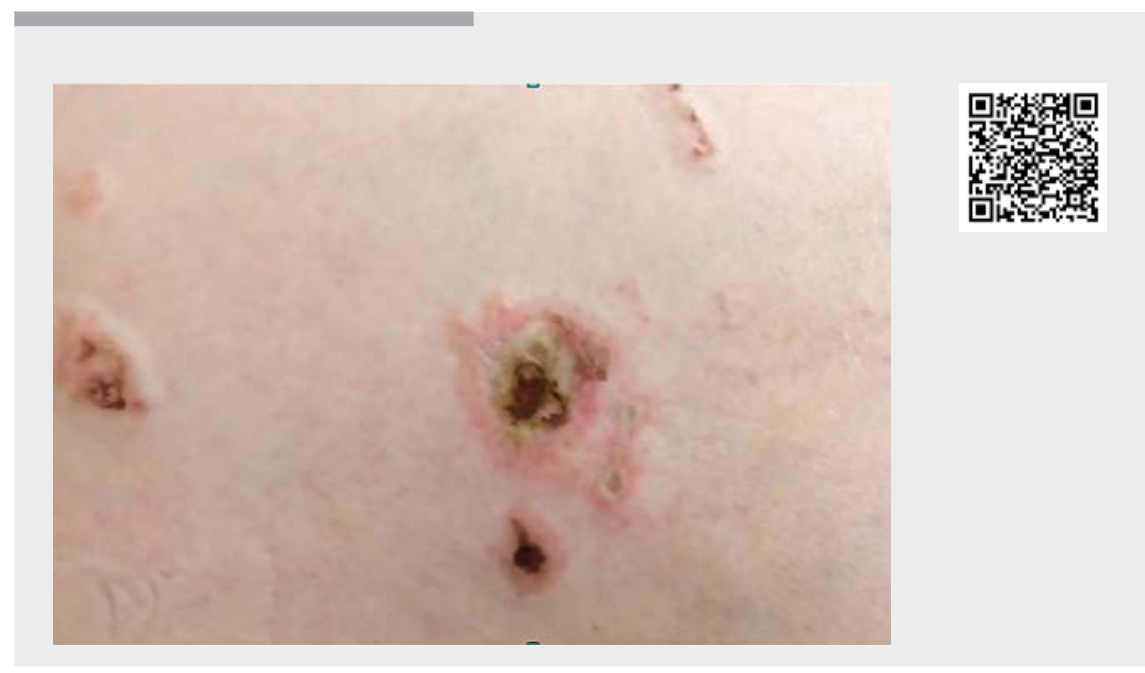

Video 1 The skin burn.

1560 ESD-treated gastric lesions over 12 years in our clinical center. A possible explanation could be a wet electrode pad during ESD as a result of humid weather and a broken air conditioning unit. We would therefore like to remind endoscopists of the possibility of skin burns from the electrode pad and the need to keep the electrode pad dry to prevent such complication.
Endoscopy_UCTN_Code_CPL_1AN_2AG

Acknowledgments

This work was supported by the Natural Science Foundation of the Guangdong Province (No. 2018A0303100024), Three Engineering Training Funds in Shenzhen (No.SYLY201718, SYJY201714 and SYLY201801), and Technical Research and Development Project of Shenzhen (No.JCYJ20150403101028164 and No. JCYJ20170307100911479). 


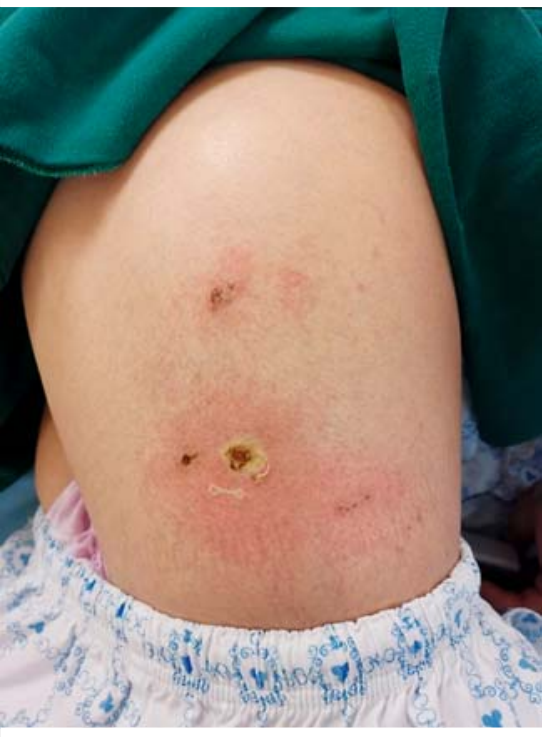

- Fig. 3 The skin burn at the site of electrode pad placement.

\section{Competing interests}

The authors declare that they have no conflict of interest.
The authors

De-feng Li, Zhi-yuan Zou, Sha Nie, Zheng-lei Xu, Li-sheng Wang

Shenzhen People's Hospital, Shenzhen,

Guangdong, China

Corresponding author

\section{Zheng-lei Xu, MD}

Department of Gastroenterology, Shenzhen People's Hospital, No.1017, Dongmen North Road, Luo hu District, Shenzhen 518020,

P. R. China

Fax: +86-755-25533118

78249073@qq.com

\section{References}

[1] Pimentel-Nunes P, Dinis-Ribeiro M, Ponchon T et al. Endoscopic submucosal dissection: European Society of Gastrointestinal Endoscopy (ESGE) Guideline. Endoscopy 2015; 47: 829-854

[2] Miyagi M, Yoshio T, Hirasawa T et al. Precordial skin burns after endoscopic submucosal dissection for gastric tube cancer. Dig Endosc 2015; 27: 743-747
Bibliography

Endoscopy 2021; 53: E179-E180

DOI 10.1055/a-1216-0897

ISSN 0013-726X

published online 20.8.2020

(c) 2020. Thieme. All rights reserved.

Georg Thieme Verlag KG, Rüdigerstraße 14,

70469 Stuttgart, Germany

\section{ENDOSCOPY E-VIDEOS \\ https://eref.thieme.de/e-videos}

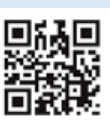

Endoscopy E-Videos is a free access online section, reporting on interesting cases and new

techniques in gastroenterological endoscopy. All papers include a high quality video and all contributions are freely accessible online.

This section has its own submission website at https://mc.manuscriptcentral.com/e-videos 